\title{
Maternal Near-Miss as a Surrogate Indicator of the Quality of Obstetric Care: A Study in a Tertiary Care Hospital in Eastern India
}

\author{
Vinita Singh $^{1}$, Archana Barik ${ }^{1}$ \\ 1. Obstetrics and Gynaecology, Tata Main Hospital, Jamshedpur, IND
}

Corresponding author: Archana Barik, archana.barik@tatasteel.com

\section{Abstract \\ Background}

Monitoring severe acute maternal morbidity or maternal near-miss is currently proposed by WHO as a valuable tool to assess the quality of obstetric care and implement new strategies for improving maternal health.

\section{Aim and objective}

The objective of this study was to assess and analyze the incidence of maternal near-miss (MNM) and maternal death (MD) at Tata Main Hospital, Jamshedpur, a tertiary care hospital in eastern India.

\section{Material and method}

This study was a prospective observational study conducted at Tata Main Hospital from November 2016 to October 2019. The study population included all the pregnant women who fulfilled the WHO near-miss criteria based on organ dysfunction or failure and all the maternal deaths that occurred during the study period.

\section{Results}

During the study period, there were 15,377 deliveries and 14,636 live births. The MNM cases were 153, and 38 were maternal deaths. The maternal near-miss ratio (MNMR) and severe maternal outcome ratio (SMOR) were 19.9 and 13.1 per 1000 live births, respectively. The maternal near-miss to mortality ratio (MNM: 1 MD) was $4: 1$, and the mortality index (MI) was $19.9 \%$. Haemorrhagic disorders were the leading cause (40.5\%) of MNM, followed by hypertensive disorders (25.5\%) and cardiac diseases (14.4\%). Similarly, both haemorrhage (23.7\%) and sepsis (23.7\%) were the leading causes of death followed by hypertensive disorders (15.8\%). On reviewing patients, $62 \%$ of near-miss and $92 \%$ of mortality cases had shown organ dysfunction on admission.

Review began $12 / 16 / 2020$ Review ended 12/26/2020 Published 01/07/2021

\section{() Copyright 2021}

Singh et al. This is an open access article distributed under the terms of the Creative Commons Attribution License CC-BY 4.0., which permits unrestricted use, distribution, and reproduction in any medium, provided the original author and source are credited.

\section{Conclusion}

MNM and MD cases share similar pathology with a different outcome. Hence, monitoring a larger volume of MNM cases helps in identifying the causes of maternal adverse events and finding out the gaps in the management more effectively than auditing only the maternal deaths.

Categories: Obstetrics/Gynecology, Epidemiology/Public Health
Keywords: maternal near-miss, maternal death, obstetric care

\section{Introduction}

Reduction in maternal mortality is an essential component of the millennium development goal (MDG) [1]. Despite a significant decline in the number of maternal death, the rate of decline is less than half of what is needed to achieve the MDG target. Resource-limited countries like India and other Asian and African countries take the maximum burden where a woman's lifetime risk of dying during pregnancy and childbirth continues to be high as compared to developed countries.

Nevertheless, maternal deaths are just the tip of the iceberg. The broad base of this iceberg represents many more women who may have nearly died from life-threatening conditions but survived. These are the maternal near-miss cases, defined as a woman who nearly died but survived a complication that occurred during pregnancy, childbirth, or within 42 days of termination of pregnancy [2]. Maternal death is traditionally used by epidemiologists and caregivers as an indicator of maternal health status at all levels starting from a community to the whole country. 


\section{Cureus}

However, with continuously declining national figures, the absolute number of maternal mortality in an area or a community may be smaller, and the analysis of a smaller sample size of maternal deaths may not reveal the actual gaps in the health care delivery system. Hence, reviewing the near-miss cases which have a larger sample size can unravel the lacunae more effectively.

Near-miss data is also a tool for policymakers to envisage the requirements of essential and emergency obstetric care, and is helpful in designing, implementing, and following up safe motherhood programs. Therefore, recently many institutions and health care facilities across the world have started reviewing nearmiss cases as an effective audit of maternal care.

\section{Materials And Methods}

This study was a prospective observational study carried out in the Department of Obstetrics and Gynaecology, Tata Main Hospital, Jamshedpur, a tertiary care hospital in the state of Jharkhand, India. This hospital is a 914-bedded facility with a 32-bedded intensive care unit (ICU), 16-bedded high dependency unit (HDU), and 24-hours blood bank facility. The Obstetrics and Gynaecology (O\&G) department has a state-ofthe-art 19-bedded labour room that is manned round-the-clock for emergency services. Apart from that, the labour room has five HDU beds that cater to high-risk pregnancies and obstetric emergencies and act as the resuscitation bay. This hospital has a large patient base, and it provides healthcare facilities not only to Jamshedpur but also from other parts of the state.

The study population included all the pregnant women admitted to Tata Main Hospital from November 2016 to October 2019. Based on the clinical audit, the patients who had severe maternal complications, and those who underwent critical interventions or needed ICU admissions (Table 1) were identified. Among them, the patients who fulfil the WHO near-miss criteria based on organ function dysfunction or failure were considered as eligible cases (Table 2). During this period, maternal deaths were also registered.

Severe maternal complications

Severe postpartum hemorrhage

Severe pre-eclampsia

Eclampsia

Sepsis or severe systemic infection

Ruptured uterus

\section{Critical interventions}

Admission to the intensive care unit

Interventional radiology

Laparotomy (includes hysterectomy, excludes cesarean section)

Use of blood products (transfusion of blood or red cells ( $\geq 5$ units)

Interventional radiology

Severe complications of abortion

Ruptured ectopic pregnancy

TABLE 1: Criteria for eligible patients (who had severe maternal complications and or critical interventions) 


\section{Cureus}

\begin{tabular}{|c|c|}
\hline Organ system dysfunction or failure & Criteria \\
\hline \multirow{5}{*}{ Cardiovascular dysfunction } & Shock \\
\hline & Cardiac arrest and cardiopulmonary resuscitation \\
\hline & Use of continuous vasoactive drugs \\
\hline & Severe hypoperfusion (lactate $>5 \mathrm{mmol} / \mathrm{l}$ or $>45 \mathrm{mg} / \mathrm{dl}$ ) \\
\hline & Severe acidosis $(\mathrm{pH}<7.1)$ \\
\hline \multirow{5}{*}{ Respiratory dysfunction } & Acute cyanosis \\
\hline & Gasping \\
\hline & Respiratory rate $>40$ or $<6$, \\
\hline & Intubation and ventilation (not related to anesthesia) \\
\hline & Severe hypoxemia $\left(\mathrm{O}_{2}\right.$ saturation $<90 \%$ for $\geq 60$ minutes or $\left.\mathrm{PaO}_{2} / \mathrm{FiO}_{2}<200\right)$ \\
\hline \multirow{3}{*}{ Renal dysfunction } & Oliguria non-responsive to fluids or diuretics \\
\hline & Dialysis for acute renal failure \\
\hline & Severe acute azotemia (creatinine $\geq 3.5 \mathrm{mg} / \mathrm{dl}$ ) \\
\hline \multirow{2}{*}{ Coagulation/hematological dy } & Severe acute thrombocytopenia $(<50000$ platelets $/ \mathrm{ml}$ ) \\
\hline & PT or aPTT > 1.5 times of normal \\
\hline \multirow{2}{*}{ Hepatic dysfunction } & Jaundice in the presence of pre-eclampsia \\
\hline & severe acute hyperbilirubinemia (bilirubin >6.0 mg/dl) \\
\hline \multirow{4}{*}{ Neurological dysfunction } & Prolonged unconsciousness (lasting $\geq 12$ hours) \\
\hline & Coma (Incluaing metabolic coma) \\
\hline & Stroke \\
\hline & ncontrollable fits/status epileptic \\
\hline
\end{tabular}

\section{TABLE 2: Near-miss criteria based on organ dysfunction or failure}

$\mathrm{PaO}_{2}$ - arterial oxygen partial pressure; $\mathrm{FiO}_{2}$ - fractional inspired oxygen; PT- prothrombin time; aPTT- activated partial thromboplastin time

The patient characteristics including age, parity, and gestational age at admission were recorded. Antenatal booking status which is defined as more than three antenatal visits to our hospital irrespective of the gestational age was also noted. Apart from that, the condition of the patients during admission, the mode of delivery, the primary cause of morbidity, the sequence of morbidity, organ dysfunction, and the key interventions was recorded. All the cases were followed up during their hospital stay till their discharge or death. The following indicators were calculated; maternal near-miss (MNM), maternal death (MD), severe maternal outcome ratio (SMOR = MNM+ MD per 1000 live births), MNM ratio (MNMR = MNM per 1000 Live births), maternal near-miss: mortality ratio (MNM: 1MD), and mortality index [MI = MD/ (MNM + MD)].

\section{Data collection}

All needed data were extracted from the medical records and entered into a study proforma. Individual participants of the study were not interviewed, since no information was directly obtained from the patients. Confidential information about the identity of the individual participants like name, medical registration number, and the date of hospital admission was kept undisclosed by the data collector. As there was no direct interaction with participants, informed consent from the individual patients was not obtained. However, permission from the institutional ethical review committee had been obtained before conducting this study. The data from individual patients were audited and analyzed weekly in a departmental review meeting led by the head of the department (the author of this paper).

\section{Results}




\section{Cureus}

There was a total of 15,377 deliveries and 14,636 live births during the study period. The total number of eligible patients was 345 and out of which 153 patients identified as maternal near-miss cases. There were 38 maternal deaths registered during the study period. The demographic parameters near-miss and mortality cases are shown in Table 3. In the near-miss group, $64 \%$ of patients were between the age of 20 to 29 years. In the mortality group, $68.4 \%$ of patients were between 25 to 34 years of age. Both morbidity and mortality were higher in multigravida patients. In the near-miss group, $60 \%$ of women were more than 28 weeks of gestation on admission, whereas in the mortality group, patients were evenly distributed in the prenatal and postnatal category. Approximately $84 \%$ of the near-miss and $92 \%$ of the mortality group were un-booked (no prior antenatal visit).

\begin{tabular}{|c|c|c|}
\hline Patients characteristics & Near Miss n (\%) $(\mathrm{N}=153)$ & Maternal Death $\mathrm{n}(\%) \quad(\mathrm{N}=38)$ \\
\hline \multicolumn{3}{|l|}{ Age } \\
\hline$\leq 19$ & $15(9.8)$ & $2(5.3)$ \\
\hline $20-24$ & $58(37.9)$ & $10(26.3)$ \\
\hline $25-29$ & $40(26.1)$ & $12(31.6)$ \\
\hline 30-34 & $24(15.7)$ & $14(36.8)$ \\
\hline$\geq 35$ & $16(10.5)$ & $0(0)$ \\
\hline \multicolumn{3}{|l|}{ Gravida } \\
\hline Primigravida & $57(37.3)$ & $10(26.3)$ \\
\hline Multigravida & $96(62.7)$ & $28(73.7)$ \\
\hline \multicolumn{3}{|l|}{ Gestational Age (Weeks) } \\
\hline 1-12 & $24(15.7)$ & $2(5.3)$ \\
\hline $13-28$ & $14(9.2)$ & $0(0)$ \\
\hline$>28$ & $92(60.1)$ & $20(52.6)$ \\
\hline Post Natal & $23(15)$ & $16(42.1)$ \\
\hline \multicolumn{3}{|l|}{ Status of antenatal Booking } \\
\hline Booked & $24(15.7)$ & $3(7.9)$ \\
\hline Un-Booked & $129(84.3)$ & $35(92.1)$ \\
\hline
\end{tabular}

TABLE 3: Patient characteristics of near-miss cases and maternal deaths

Various quality indicators were calculated year-wise and displayed in Table 4 . The average maternal mortality rate (MMR) and maternal near-miss ratio (MNMR) in the study period were 259.6 and 10.5, respectively. 


\section{Cureus}

\begin{tabular}{|c|c|c|c|c|}
\hline Quality Indicators & 2016-17 & 2017-18 & 2018-19 & Total \\
\hline Live Birth & 5168 & 4440 & 5028 & 14636 \\
\hline Maternal Near-Miss (MNM) & 64 & 56 & 33 & 153 \\
\hline Maternal Death (MD) & 19 & 09 & 10 & 38 \\
\hline Maternal Mortality Ratio (MMR) & 367.6 & 202.7 & 198.9 & 259.6 \\
\hline Severe maternal outcome ratio (SMOR) & 16.1 & 14.6 & 8.6 & 13.1 \\
\hline MNM incidence ratio (MNMIR) & 12.4 & 12.6 & 6.56 & 10.5 \\
\hline Maternal near-miss: mortality ratio (MNM: 1MD) & 3.4:1 & $6.2: 1$ & 3.3:1 & 4:1 \\
\hline Mortality index (MI) & $22.9 \%$ & $13.8 \%$ & $23.3 \%$ & $19.9 \%$ \\
\hline
\end{tabular}

TABLE 4: Year-wise data of maternal near-miss, maternal death, and various quality indicators

Cesarean section accounted for $56.2 \%$ and $57.9 \%$ of delivery in near miss and mortality cases, respectively (Table 5). In the near-miss group, $14.4 \%$ of women underwent vaginal delivery as compared to $23.7 \%$ in the mortality group.

\begin{tabular}{|c|c|c|}
\hline Pregnancy Outcome & Maternal Near Miss $n(\%) \quad(\mathrm{N}=153)$ & Maternal Death $\mathrm{n}(\%) \quad(\mathrm{N}=38)$ \\
\hline Vaginal Delivery & $22(14.4)$ & $9(23.7)$ \\
\hline Cesarean Section & $86(56.2)$ & $22(57.9)$ \\
\hline Laparotomy for ectopic pregnancy & $20(13.1)$ & 0 \\
\hline Curettage/vacuum aspiration & $15(9.8)$ & $1(2.6)$ \\
\hline Others & $10(6.5)$ & $6(15.8)$ \\
\hline
\end{tabular}

\section{TABLE 5: Outcome of pregnancy in maternal near-miss cases and maternal deaths}

Hemorrhagic disorders of pregnancy were the leading cause of near-miss (40.5\%), followed by hypertensive disorder (25.5\%), cardiac illness (14.4\%), and sepsis (7.8\%). Both hemorrhage (23.7\%) and sepsis (23.7\%) constituted the leading causes of mortality, followed by hypertensive disorders of pregnancy (15.8\%). Moreover, the post-partum hemorrhage, eclampsia, sepsis, and peripartum cardiomyopathy were the independent conditions associated with higher morbidity and mortality (Tables 6-9).

\begin{tabular}{|c|c|c|}
\hline Underlying disorder & Maternal near-miss $n(\%)(n=153)$ & Maternal death $n(\%)(n=38)$ \\
\hline Hemorrhagic disorders of pregnancy & $62(40.5)$ & $9(23.7)$ \\
\hline Hypertensive disorders of pregnancy & 39 (25.5) & $6(15.8)$ \\
\hline Cardiac diseases & $22(14.4)$ & $3(7.9)$ \\
\hline Sepsis or severe systemic infection & $12(7.8)$ & $9(23.7)$ \\
\hline Hepatic disorder & $11(7.2)$ & $3(7.9)$ \\
\hline Dengue fever & 0 & $3(7.9)$ \\
\hline Other medical or surgical conditions & $6(3.9)$ & 5 (13.2) \\
\hline
\end{tabular}

TABLE 6: Underlying disorders in maternal near-miss cases and maternal deaths 


\section{Cureus}

Hemorrhagic disorders

Post-partum hemorrhage

Antepartum hemorrhage

Ruptured uterus

Ruptured ectopic pregnancy

Incomplete abortion
Maternal near miss n (\%) $(n=62)$

21 (33.9)

$11(17.7)$

9 (14.5)

$15(24.2)$

$6(9.7)$
Maternal death $\mathrm{n}(\%)(\mathrm{n}=9)$

8 (88.9)

1 (11.1)

0

0

0

TABLE 7: Types of hemorrhagic disorder in maternal near-miss cases and maternal deaths

\begin{tabular}{|c|c|c|}
\hline Hypertensive disorders & Maternal Near miss n (\%) $(\mathbf{N}=39)$ & Maternal Death $\mathrm{n}(\%) \quad(\mathrm{N}=6)$ \\
\hline Severe Preeclampsia & $9(23.1)$ & 0 \\
\hline Eclampsia & $28(71.8)$ & $6(100)$ \\
\hline HELPP Syndrome & $2(5.1)$ & 0 \\
\hline
\end{tabular}

TABLE 8: Types of hypertensive disorder in maternal near-miss cases and maternal deaths

\begin{tabular}{|c|c|c|}
\hline Cardiac diseases & Maternal near miss n (\%) (N = 22) & Maternal death $n(\%)(n=3)$ \\
\hline Valvular heart disease & $8(36.4)$ & 0 \\
\hline Peripartum cardiomyopathy & $9(40.9)$ & $3(100)$ \\
\hline Congenital heart disease & $2(9.1)$ & 0 \\
\hline Others & $3(13.6)$ & 0 \\
\hline
\end{tabular}

TABLE 9: Types of cardiac disease in maternal near-miss cases and maternal deaths

Table 10 depicts the organ dysfunction associated with near-miss and mortality groups. On audit of these cases, we found that $62 \%$ of near-miss and $92 \%$ of mortality group patients admitted with one or more organ dysfunction on admission. Moreover, $22.9 \%$ of near-miss and $7.9 \%$ mortality group patients admitted with a disorder but without any organ dysfunction but later developed it during their stay in hospital. Only $15 \%$ of patients in the near-miss group were healthy on admission (Table 11). 


\section{Cureus}

\begin{tabular}{|c|c|c|}
\hline Organ dysfunction & Maternal near miss $n(\%)(n=153)$ & Maternal Death $n(\%)(n=38)$ \\
\hline Cardiovascular dysfunction & $31(20.3)$ & $6(15.8)$ \\
\hline Respiratory dysfunction & $11(7.2)$ & 0 \\
\hline Renal dysfunction & $09(5.9)$ & 0 \\
\hline Coagulation/hematologic dysfunction & $24(15.7)$ & $8(21)$ \\
\hline Hepatic dysfunction & $14(9.2)$ & $2(5.3)$ \\
\hline Neurologic dysfunction & $27(17.6)$ & $5(13.2)$ \\
\hline Uterine dysfunction/hysterectomy & $15(9.8)$ & 0 \\
\hline Multiorgan Dysfunction & 22 (14.4) & $14(36.8)$ \\
\hline
\end{tabular}

TABLE 10: Organ dysfunction in maternal near-miss cases and maternal deaths

\begin{tabular}{|c|c|c|}
\hline On admission status of cases & Maternal near miss $n(\%)(n=153)$ & Maternal death $n(\%)(n=38)$ \\
\hline Cases presenting with organ dysfunction on admission & $95(62.1)$ & $35(92.1)$ \\
\hline Cases admitted with disorder developed organ dysfunction & $35(22.9)$ & $3(7.9)$ \\
\hline Cases admitted without any disorder developed organ dysfunction & $23(15)$ & 0 \\
\hline
\end{tabular}

TABLE 11: Status of maternal near-miss and maternal death cases on admission to the hospital

\section{Discussion}

MMR has been used by healthcare planners as the yardstick to assess the quality of obstetric services in an area. Lately, the focus has shifted from maternal mortality to maternal near-miss as a more valuable indicator of maternal health [3].

However, there was a lack of clarity in the inclusion criteria of near-miss cases. Near-miss cases were either identified based on disease [4] or critical intervention (Hysterectomy, ICU admission, etc.) [5] or organdysfunction [6] using laboratory parameters with pros and cons in each criterion. Recently, the WHO expert group authorized organ system failure or dysfunction-based criteria as the standard in identifying near-miss cases [2]. In this study, the WHO near-miss criteria based on organ dysfunction or failure was used. Patients merely having an obstetric complication without any derangement in laboratory parameters or patients who needed ICU admission for postoperative monitoring without any systemic disorder or organ dysfunction were not categorized as near-miss.

The MMR in our hospital during the study period was 259.6 , which was much higher compared to the national figure of 130 [7]. That probably due to the lack of adequate health infrastructure and services in the surrounding areas, (East Singhbhum district, Jharkhand) especially in the remote rural areas. According to government data, there are only nine PHCs (primary health centre), 16 APHCs (additional public health centre), and 242 HSCs (health sub-centre) catering to a population close to 23 lakhs, which is much less than the national recommendation (a PHC for every 30,000 population) [8-9]. The MNMR (number of maternal near-miss cases per 1,000 live births) was 10.5 in our study, and the severe maternal outcome ratio (SMOR), which refers to the number of women with life-threatening conditions including death, was 13.1. Both MNMR and SMOR give an estimate of the amount of care and resources that would be needed to improve obstetric care in that area or facility. We reviewed studies done in different parts of India, and the near-miss ratio ranged from 120 to 10.4 (Table 12) [10-22]. However, all these studies have used different criteria in identifying near-miss cases and hence technically not ideal for comparison. In other subcontinent countries, the incidence of the near-miss was 5.5, 26.8, and 7.13 in studies conducted in Sri Lanka [23], Bangladesh [24], and Pakistan [25], respectively. 


\section{Cureus}

\begin{tabular}{|c|c|c|c|c|c|c|c|c|c|}
\hline Author & Year & Setting & Criteria for near-miss & LB & MMR & MNMR & MNMMR & MI & $\begin{array}{l}\text { Near miss } \\
\text { conditions }\end{array}$ \\
\hline PS [10] & 2013 & $\begin{array}{l}\text { Tertiary care hospital, } \\
\text { Manipal }\end{array}$ & $\begin{array}{l}\text { Disease-specific management } \\
\text { based }\end{array}$ & 7330 & 313 & 17.8 & $5.6: 1$ & 14.9 & $\begin{array}{l}\text { Haemorrhage } \\
\text { (44.2), } \\
\text { hypertension } \\
\text { (23.6), sepsis }\end{array}$ \\
\hline Pandey [11] & 2014 & $\begin{array}{l}\text { Medical college, } \\
\text { Lucknow }\end{array}$ & Management based & 5,273 & 4,684 & 120 & 2.6:1 & - & $\begin{array}{l}\text { Haemorrhage } \\
(45.7), \\
\text { hypertension } \\
(23.6)\end{array}$ \\
\hline Bakshi [12] & 2015 & $\begin{array}{l}\text { Multicentre trial, } \\
\text { Dehradun }\end{array}$ & Disease-specific & 688 & 1453 & 74 & $5.1: 1$ & 16.4 & $\begin{array}{l}\text { Sepsis (58.8), } \\
\text { hemorrhage } \\
(37.2) \text {, } \\
\text { hypertension } \\
(23.5)\end{array}$ \\
\hline Singh [13] & 2016 & $\begin{array}{l}\text { Tertiary care hospital, } \\
\text { Raipur }\end{array}$ & $\begin{array}{l}\text { Disease-specific management } \\
\text { based organ dysfunction }\end{array}$ & 13,895 & 734 & 15.2 & $2: 1$ & 32.58 & $\begin{array}{l}\text { Hypertension } \\
(38.8), \\
\text { haemorrhage } \\
(22.2)\end{array}$ \\
\hline Parmar [14] & 2016 & $\begin{array}{l}\text { Tertiary care hospital, } \\
\text { Vadodara }\end{array}$ & $\begin{array}{l}\text { Disease-specific management } \\
\text { based laboratory criteria }\end{array}$ & 1929 & 933 & 23.8 & 2.6:1 & 28.1 & - \\
\hline Rathod [15] & 2016 & $\begin{array}{l}\text { Tertiary care hospital, } \\
\text { Yavatmal }\end{array}$ & Organ dysfunction & 22,092 & 298.7 & 7.3 & 3.4:1 & 29.07 & $\begin{array}{l}\text { Haemorrhage } \\
\text { (26.7), anaemia } \\
\text { (24.8), hepatitis } \\
\text { (16.7) }\end{array}$ \\
\hline Sinha [16] & 2016 & $\begin{array}{l}\text { Medical college, } \\
\text { Bareilly }\end{array}$ & $\begin{array}{l}\text { Management based (ICU } \\
\text { admission) }\end{array}$ & 8051 & 484.4 & 10.8 & 2.2:1 & - & $\begin{array}{l}\text { Hypertension } \\
(22.2)\end{array}$ \\
\hline Ray [17] & 2016 & $\begin{array}{l}\text { Tertiary care hospital, } \\
\text { Karad }\end{array}$ & Disease-specific & 4038 & 421 & 54.5 & 13:1 & 7.17 & $\begin{array}{l}\text { Hypertension } \\
\text { (56), } \\
\text { haemorrhage } \\
\text { (11) }\end{array}$ \\
\hline $\begin{array}{l}\text { Chandak } \\
\text { [18] }\end{array}$ & 2017 & $\begin{array}{l}\text { Medical college, } \\
\text { Nagpur }\end{array}$ & $\begin{array}{l}\text { Disease-specific management } \\
\text { based organ dysfunction }\end{array}$ & 12757 & 243 & 10.7 & 4.4:1 & - & $\begin{array}{l}\text { Hypertension, } \\
\text { haemorrhage }\end{array}$ \\
\hline $\begin{array}{l}\text { Tallapureddy } \\
\text { [19] }\end{array}$ & 2017 & $\begin{array}{l}\text { Medical college, } \\
\text { Hyderabad }\end{array}$ & $\begin{array}{l}\text { Disease-specific management } \\
\text { based }\end{array}$ & 3784 & 158.5 & 8.4 & 5.3:1 & 15.79 & $\begin{array}{l}\text { Haemorrhage } \\
(43.7 \%) \text {, } \\
\text { hypertension } \\
(31.2 \%)\end{array}$ \\
\hline Gupta [20] & 2018 & Medical college, Indore & $\begin{array}{l}\text { Disease-specific management } \\
\text { based organ dysfunction }\end{array}$ & 4533 & 330.9 & 16.3 & $3.5: 1$ & 22.1 & $\begin{array}{l}\text { Haemorrhage } \\
\text { (40.5), } \\
\text { hypertension } \\
(24.3) \text {, sepsis } \\
(13.5)\end{array}$ \\
\hline Mansuri [21] & 2019 & $\begin{array}{l}\text { Four tertiary care } \\
\text { hospitals, Ahmedabad }\end{array}$ & Organ dysfunction & 21,491 & 367.6 & 11.49 & 3.13:1 & 24.23 & $\begin{array}{l}\text { Hypertension, } \\
\text { haemorrhage }\end{array}$ \\
\hline Verma [22] & 2020 & $\begin{array}{l}\text { Tertiary care hospital, } \\
\text { Etawah }\end{array}$ & Disease-specific & 8638 & 891.4 & 16.6 & 1.9:1 & 34.8 & $\begin{array}{l}\text { Hypertension } \\
(45.7), \\
\text { hemorrhage } \\
(23.5)\end{array}$ \\
\hline
\end{tabular}

\section{TABLE 12: List of studies on maternal near-miss done in different parts of India}

LB: live birth; MMR: maternal mortality ratio; MNMR: maternal near-miss ratio; MNMMR: maternal near-miss mortality ratio; MI: mortality index

The indicators relating near miss and mortality (maternal near-miss mortality ratio and mortality index) 
represent a fair account of overall available health resources and the quality of health care in that area. Maternal near-miss mortality ratio (MNMMR) refers to the ratio between maternal near-miss cases and maternal deaths, and a higher ratio indicates better quality of care as more women survived than died. Similarly, the mortality index represents the percentage of the patient with life-threatening conditions who ultimately die. In this case, a higher value means more women with life-threatening conditions die, indicating the low quality of care and vice versa [2]. In our study, MNMMR was 4:1, and the mortality index was 19.9, which is comparable to most of the Indian studies.

As expected, in resource-limited countries like India, more women suffer and die as compared to the European countries, mainly due to lacunae in managing obstetric emergencies at various levels. Three delays have been identified, which are believed to be the reason for poor obstetric emergency care in the Indian setup [26]. The first delay is the lack of awareness leading to delay in availing health care facilities. The second delay is inaccessibility to health care due to lack of transport, cost, or socioeconomic issues. The third delay is related to lack of proper care at the health care facility due to the delay in diagnosis of critical conditions or decision making or unavailability of resources or trained health care provider. On analyzing this aspect in our study, we found that $92 \%$ of maternal deaths and $62 \%$ of near-miss cases were having one or more organ dysfunction on admission, which suggests that the first and the second delays could be the primary reason for the high morbidity and mortality in our study. This hypothesis is also indirectly supported by the fact that about $84 \%$ of patients of near-miss and $92 \%$ of maternal death were un-booked (no prior antenatal visit).

Like most of the Indian studies, haemorrhage (40.5\%) accounted for the leading cause of morbidity, followed by hypertensive disorders (25.5\%) in our study. Conversely, both sepsis and haemorrhage were responsible for almost half of the cases of maternal death. Post-partum haemorrhage and eclampsia constituted the major complications among hemorrhagic disorder and in the hypertensive disease group, respectively. Peripartum cardiomyopathy (40.9\%) was the leading cause of cardiac morbidity in our study, and it was the only cause of cardiac-related maternal mortality. That was unlike in most parts of India, where rheumatic heart disease and congenital heart diseases were the leading cause of morbidity and mortality [27-28]. It may be because most of the valvular heart diseases were diagnosed early in the pregnancy and hence optimized adequately before delivery, whereas cardiomyopathies are usually diagnosed late.

A number of initiatives have been undertaken in our hospital to improve our response to obstetric emergencies over the last few years. The numbers of staff in the labour room have been augmented. Inhouse 24-hour anaesthesia service has started. An obstetric high dependency unit (HDU) has been established. Fast-tracking of blood and blood product availability from the blood bank has been streamlined. We also introduced a weekly analysis of near-miss and mortality cases to identify preventable factors and implementing protocols adhering to National Guidelines and current evidenced-based practices. In addition to that, the training of caregivers, labour room nurses, and midwives at regular intervals were strengthened. However, the impact of these quality initiatives on obstetric care needs to be quantitatively assessed by a future study.

Looking at the health care deficiencies found in our study area, there is a need to improve community-level resources and most importantly, awareness regarding antenatal visits among the public. Health care providers working in primary health centres (PHC) and community health centres (CHC) may need training in managing maternal complications, and the government should take initiatives in strengthening the referral system of sick patients to higher centres.

\section{Conclusions}

The current study was conducted to assess the incidence and causes of maternal near-miss and mortality in a tertiary care hospital situated in eastern India. The near-miss cases were identified by using the WHO criteria of near-miss. The study revealed that the near-miss cases had similar pathological courses as that of maternal mortality. Haemorrhage, hypertensive disorders, and sepsis were the major reasons for morbidity and mortality like in other parts of India. It was also observed that most of the near-miss and mortality cases didn't have a prior antenatal visit. Moreover, most of them were severely ill with pre-existing organ dysfunction on admission to the hospital, suggesting a delay in seeking proper care or delay in reaching the health-care facility. A limitation of this study was that it involves only the patients coming to a single tertiary care hospital. Hence, extrapolating the data of this study to the whole population of this area may be erroneous. A further study may be warranted to evaluate the root causes of the health care gaps at the community level. To conclude, maternal near-miss can be compared with the black box of an aircraft as they survived from similar complications to that of maternal mortality and they are alive to provide useful information regarding the inadequacies in maternal health care.

\section{Additional Information \\ Disclosures}

Human subjects: Consent was obtained by all participants in this study. Institutional Ethics Committee, Tata Main Hospital, Jamshedpur, India issued approval N/A. This study was observational, and there was no 
active participation of patients in any part of the study. Hence, informed consent of patients has been waived, and the Institutional Review Board or ethics committee approval was not needed. Animal subjects: All authors have confirmed that this study did not involve animal subjects or tissue. Conflicts of interest: In compliance with the ICMJE uniform disclosure form, all authors declare the following: Payment/services info: All authors have declared that no financial support was received from any organization for the submitted work. Financial relationships: All authors have declared that they have no financial relationships at present or within the previous three years with any organizations that might have an interest in the submitted work. Other relationships: All authors have declared that there are no other relationships or activities that could appear to have influenced the submitted work.

\section{Acknowledgements}

The authors would like to acknowledge the contributions of all the doctors of the Department of Obstetrics and Gynaecology, Tata Main Hospital, in acquiring data for this study.

\section{References}

1. The millennium development goals report. (2015). Accessed: 1 June 2020: https://www.un.org/millenniumgoals/2015_MDG_Report/pdf/MDG\%202015\%20rev\%20(July\%201).pdf.

2. World Health Organization (WHO). Evaluating the quality of care for severe pregnancy complications: the WHO near-miss approach for maternal health. (2011). Accessed: 11 July 2020: https://www.who.int/reproductivehealth/publications/monitoring/9789241502221/en/.

3. Say L, Pattinson RC, Gülmezoglu AM: WHO systematic review of maternal morbidity and mortality: the prevalence of severe acute maternal morbidity (near miss). Reprod Health. 2004, 17:3. 10.1186/1742-47551-3

4. Filippi V, Ronsmans C, Gohou V, et al.: Maternity wards or emergency obstetric rooms? Incidence of nearmiss events in African hospitals. Acta Obstet Gynaecol Scand. 2005, 84:11-6.

5. Waterstone M, Bewley S, Wolfe C: Incidence \& predictors of severe obstetric morbidity: case-control study . BMJ. 2001, 322:1089-94. 10.1136/bmj.322.7294.1089

6. Mantel GD, Buchmann E, Rees H, Pattinson RC: Severe acute maternal morbidity: a pilot definition for near miss. Br J Obstet Gynaecol. 1998, 105:985-90. 10.1111/j.1471-0528.1998.tb10262.x

7. Maternal mortality ratio in India. (2016). Accessed: 23 November 2020: https://niti.gov.in/content/maternal-mortality-ratio-mmr-100000-live-births.

8. Department of Health, East Singhbhum, Government of Jharkhand . (2020). Accessed: 17 December 2020: https://jamshedpur.nic.in/health/.

9. Indian public health standards (IPHS) guidelines for primary health centres . (2012). Accessed: 18 December 2020: https://nhm.gov.in/images/pdf/guidelines/iphs/iphs-revised-guidlines-2012/primay-healthcentres.pdf.

10. PS R, Verma S, Rai L, Kumar P, Pai MV, Shetty J: “Near miss” obstetric events and maternal deaths in a tertiary care hospital: an audit. J Pregnancy. 2013, 2013:393758. 10.1155/2013/393758

11. Pandey A, Das V, Agarwal A, Agrawal S, Misra D, Jaiswal N: Evaluation of obstetric near miss and maternal deaths in a tertiary care hospital in north India: shifting focus from mortality to morbidity. J Obstet Gynaecol India. 2014, 64:394-9. 10.1007/s13224-014-0552-1

12. Bakshi RK, Aggarwal P, Roy D, Nautiyal R, Kakkar R: Indicators of maternal 'near miss' morbidity at different levels of health care in North India: a pilot study. Bangladesh J Med Sci. 2015, 14:254-7.

13. Abha S, Chandrashekhar S, Sonal D: Maternal near miss: a valuable contribution in maternal care . J Obstet Gynaecol India. 2016, 66:217-22. 10.1007/s13224-015-0838-y

14. Parmar NT, Parmar AG, Mazumdar VS: Incidence of maternal “near-miss” events in a tertiary care hospital of Central Gujarat, India. J Obstet Gynaecol India. 2016, 66:315-20. 10.1007/s13224-016-0901-3

15. Rathod AD, Chavan RP, Bhagat V, Pajai S, Padmawar A, Thool P: Analysis of near-miss and maternal mortality at tertiary referral centre of rural India. J Obstet Gynaecol India. 2016, 66:295-300. 10.1007/s13224-016-0902-2

16. Sinha M, Goel JK, Sah S, Goel R, Chaurasia R: Severe acute maternal morbidity: study of epidemiology and risk factors. Int J Reprod Contracept Obstet Gynecol. 2016, 5:2141-2145. 10.18203/23201770.ijrcog20162080

17. Ray N, Patil SK, Kshirsagar NS, Patil Y, Laddad M: Maternal near miss in a tertiary care hospital: a cross sectional study. J Evol Med Dent Sci. 2016, 5:3352-4. 10.14260/jemds/2016/755

18. Chandak PO, Kedar KV: Maternal near miss- a review from tertiary care hospital . J Evol Med Dent Sci. 2017, 6:3633-7. 10.14260/Jemds/2017/783

19. Tallapureddy S, Velagaleti R, Palutla H, Satti CV: "Near-Miss" obstetric events and maternal mortality in a tertiary care hospital. Indian J Public Health. 2017, 61:305-308. 10.4103/ijph.IJPH_268_16

20. Gupta D, Nandi A, Noor N, Joshi T, Bhargava M: Incidence of maternal near miss and mortality cases in central India tertiary care centre and evaluation of various causes. New Indian J OBGYN. 2018, 4:112-6. 10.21276/obgyn.2018.4.2.4

21. Mansuri F, Mall A: Analysis of maternal near miss at tertiary level hospitals, Ahmedabad: A valuable indicator for maternal health care. Indian J Community Med. 2019, 44:217-221. 10.4103/ijcm.IJCM_267_18

22. Verma V, Kanti V, Vishwakarma S, Gupta UK, Shree P: “Near-miss” obstetric events and maternal deaths in a rural tertiary care center in North India. Cureus. 2020, 12:11828. 10.7759/cureus.11828

23. Ranatunga GA, Akbar JF, Samarathunga S, Perera YA, Kariyawasam L, Kumarasiri JM: Severe acute maternal morbidity in a tertiary care institution. Sri Lanka J Obstet Gynaecol. 2013, 34:135-143. 10.4038/sljog.v34i4.5930

24. Jahan R, Hossain MS, Shila S, Lipi L, Susan Z, Chowdhury S: Severe acute maternal morbidity (SAMM) in postpartum period requiring tertiary hospital care. Journal of Shaheed Suhrawardy Medical College. 2018, 


\section{Cureus}

8:58-62. 10.3329/jssmc.v8i2.37245

25. Mazhar SB, Batool A, Emanuel A, Khan AT, Bhutta S: Severe maternal outcomes and their predictors among Pakistani women in the WHO Multicountry Survey on Maternal and Newborn Health. Int J Gynaecol Obstet. 2015, 129:30-3. 10.1016/j.ijgo.2014.10.017

26. Chhabra P: Maternal near miss: an indicator for maternal health and maternal care. Indian J Community Med. 2014, 39:132-7. 10.4103/0970-0218.137145

27. Khan DA, Sharma N, Kapoor M, Duwarah SG, Ahanthem SS: The spectrum of heart disease in pregnancy and its outcome in patients visiting a tertiary care centre of Northeastern: a prospective study. J Clin Diagn Res. 2018, 12:16-20. 10.7860/JCDR/2018/35407.11837

28. Salam S, Mushtaq S, Mohi-ud-Din K, Gul I, Ali A: Maternal and fetal outcome in pregnancy with heart disease in tertiary care hospital in India. Int J Reprod Contracept Obstet Gynecol. 2017, 6:3947-3951. 10.18203/2320-1770.ijrcog20174041 